\title{
Coorelation of Hscrp with Urinary Albumin Creatinine Ratio(UACR) in Patients Of Diabetes with And Without Nephropathy.
}

\author{
Rahul Chauhan ${ }^{1}$, Ramendra Singh, ${ }^{2}$ Ritesh $\mathrm{Lal}^{3}$ \\ ${ }^{1}$ Post Graduate Student: Department Of Medicine, Subharti Medical College, Meerut \\ ${ }^{2}$ Assistant Professor, Department Of Medicine, Subharti Medical College, Meerut \\ ${ }^{3}$ Assistant Professor., Department Of Medicine, Subharti Medical College
}

\begin{abstract}
:
Background : Diabetic nephropathy remains major cause of morbidity \& mortality for persons with either Type l or type $2 D M^{l}$ India leads the world with largest number of diabetic subjects earning the dubious distinction of being termed the "diabetes capital of the world". Patients with type 2 diabetes comprise the largest and fastest growing single disease group requiring renal replacement therapy (nearly 50-60\% of diabetic subjects receiving renal replacement therapy. ${ }^{2}$ In the past few years, numerous studies have shown that low-grade inflammation is associated with the risk of developing type 2 DM. ${ }^{3}$ Several recent studies have also shown that patients with type $2 \mathrm{DM}$ and overt nephropathy exhibit high levels of diverse acute phase markers of inflammation, including C-reactive protein (CRP), serum amyloid A, fibrinogen, and IL- $6^{4,5,6,7,8}$ This study Was undertaken to investigate the role of subclinical inflammation in the pathogenesis of diabetic nephropathy by evaluating the association between the serum High-sensitivity CRP (HS-CRP) (marker of inflammation) and urinary albumin to urinary creatinine ratio.

Methods: A prospective case control study of 100 diabetic patients were taken(50 patients with nephropathy and 50 without nephropathy) all these patients hsCRP was compared with UACR(urine albumin to urine creatine ratio).

Result: Mean hsCRP in patients without nephropathy was $1.7046 \mathrm{mg} / \mathrm{dL}$ and Mean hsCRP in patients with nephropathy was 8.83054. This difference was found to be statistically significant ( pvalue <0.0001). Mean Hscrp in patients without macro albuminuria was $4.51 \pm 6.34$.Mean Hscrp in patients with macro albuminuria was 8.71 \pm 3.99 . This difference was found to be statistically significant ( $p$ value $=0.0089$ ).
\end{abstract}

\section{Introduction}

Many chronic diseases are now in pandemic proportions and increasingly a major cause of morbidity and mortality worldwide. Diabetes mellitus, especially type 2 diabetes, plays a starring role in this problem, ${ }^{1,2}$ with diabetic complications being a very important public health issue.. A paradigmatic example of diabetic complications is diabetic nephropathy, the largest single cause of end-stage renal disease (5-10\% of type 2 diabetic patients will develop ESRD from diabetic nephropathy (DN)2, and a med According to the Diabetes Atlas 2006 published by the Intemational Diabetes Federation, the number of people with diabetes in India currently around 40.9 million is expected to rise to 69.9 million by 2025 unless urgent preventive steps are taken. Diabetic patients in developing countries because of Asian Indian phenotype (which include increased insulin resistance, greater abdominal adiposity i.e., higher waist circmnference despite lower body mass index, lower adiponectin) are even more vulnerable to develop the micro-vascular complications of diabetes including diabetic nephropathy. ${ }^{5,8}$,

Patients with type 2 diabetes comprise the largest and fastest growing single disease group requiring renal replacement therapy (nearly 50-60\% of diabetic subjects receiving renal replacement therapy. ${ }^{6}$ Studies based in southern India have estimated that the current prevalence of o Several recent studies have also shown that patients with type $2 \mathrm{DM}$ and overt nephropathy exhibit high levels of diverse acute phase markers of inflammation, including C-reactive protein (CRP), serum amyloid A, fibrinogen, and IL. It is well known that in the general population, as well as in diabetes, these acute-phase markers are associated with increased cardiovascular risk, because chronic inflammation is one of the pathogenetic mechanisms of atherosclerosis ${ }^{11}{ }^{12,13}$. In contrast, the relationships between low grade inflammation and diabetic microangiopathy are still unclear. As far as nephropathy is concerned, several studies have examined the relationships with inflammation, leading to conflicting results ${ }^{23}$. Overall, however, most studies have reported an increase in acute-phase markers in patients with nephropathy and also in patients with microalbuminuria ${ }^{18^{2} 20^{\prime 2} 22^{\prime}}$ This study Was undertaken to investigate the role of subclinical inflammation in the pathogenesis of diabetic nephropathy by evaluating the association between the serum High-sensitivity CRP (HS-CRP) (marker of inflammation) and urinary albumin to creatinine ratio(UACR) in type2 diabetes mellitus. 


\section{Material and methods}

A prospective case control study of 100 diabetic patients were taken(50 patients with nephropathy and 50 without nephropathy) all these patients hsCRP was compared with UACR(urine albumin to urine creatine ratio)

All subjects were submitted to the following:

1.Full clinical history and clinical examination.

2.Laboratory investigations including

hsCRP

Urine albumin to creatine ratio

Hbalc

Blood urea

Serum creatinine

Urine routine microscopy

Hbsag

$\mathrm{Hcv}$

Ultrasound abdomen

Fasting blood sugar

Post Prandial blood sugar

Exclusion Criteria

Patients having a history of

- Recent Stroke(within last 6 months)

- Recent Myocardial Infarction(within last 6 months)

- Smoking

- Chronic liver disease

- Recent Infection

- Rheumatoid Arthritis

- Known case of Cancer

- Recent Surgery (within last 6 months)

- Major Trauma (within last 6 months)

\section{Results}

- Mean hsCRP in patients without nephropathy was $1.7046 \mathrm{mg} / \mathrm{dL}$ and Mean hsCRP in patients with nephropathy was 8.83054 . This difference was found to be statistically significant ( $\mathbf{p}$ value $<\mathbf{0 . 0 0 0 1}$ )

- Mean fasting blood sugar in patients without nephropathy was $167.06 \mathrm{mg} / \mathrm{dl}$ Mean fasting blood sugar in patients with nephropathy was. $181.62 \mathrm{mg} / \mathrm{dl}$. This difference was found to be statistically not significant ( $p$ value $=0.0507$ )

- Mean post prandial blood sugar level in patients without nephrapathy was $273.84 \pm 36.26$

- Mean post prandial blood sugar level in patients with nephropathy was. $298.44 \pm 42.36$. This difference was found to be statistically significant. $(\mathbf{p}$ value $\mathbf{= 0 . 0 0 2 4})$

- Mean Hba1c in patients without nephropathy was 9.14 \pm 1 .41. Mean HbA1c in patients with nephropathy was $10.06 \pm 1.70$. This difference was found to be statistically significant ( $\mathbf{p}$ value $\mathbf{= 0 . 0 0 4 0}$ )

- Mean Hscrp in patients with UACR A1 was 1.705468085 Mean hscrp in patients with UACRA2 was 8.42308. This difference was found to be highly statistically significant ( $\mathbf{p}$ value $<\mathbf{0 . 0 0 1}$ )

- Mean blood urea in patients without nephropathy was 31.266 whereas mean blood urea in patients without nephropathy was 59.676. This difference was found to be highly statistically significant ( $\mathbf{p}$ value $<\mathbf{0 . 0 0 0 1}$ )

- Mean serum creatinine in patients without nephropathy was 0.748 . Mean serum creatinine in patients with nephropathy was 1.85 . This difference was found to be statistically significant ( $\mathbf{p}$ value $<\mathbf{0 . 0 0 1}$ )

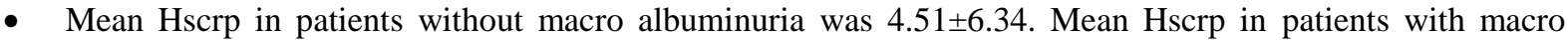
albuminuria was $8.71 \pm 3.99$. This difference was found to be statistically significant ( $\mathbf{p}$ value $=\mathbf{0 . 0 0 8 9}$ )

- Mean systolic blood pressure in patients without nephropathy was 131.2 Mean systolic blood pressure in patients with nephropathy was 151.2

- Mean hsCRP in normotensive patients was $3.351 \pm 3.82$ Mean hsCRP in hypertensive patients was $7.018 \pm 7.52$

- In the normotensive patients with no nephropathy mean hsCRP was $1.90 \pm 0.80$ and with nephropathy was $8.11 \pm 5.18$. In the hypertensive patients with no nephropathy mean hsCRP was8.11 \pm 5.18 and in patients with nephropathy was $9.08 \pm 7.74$ 


\section{Discussion}

100 Type 2 Diabetes Mellitus patients with age 18 and above to the department of medicine and were divided into 2 groups based on UACR. One group consisted of 50 Type 2 Diabetes Mellitus with UACR $<3 \mathrm{mg} / \mathrm{dl}$. Other group consisted of 50 Type 2 Diabetes Mellitus patient with UACR $>3 \mathrm{mg} / \mathrm{dl}$. HsCRP was studied in all of them in correlation with UACR. Although there is now convincing evidence that Type 2 Diabetes Mellitus includes an inflammatory component that has been related to diabetic complications. There is limited data on Type 2 Diabetes Mellitus Nephropathy in Asia .In order to find an easier method for detection of diabetic nephropathy as a screening method of diabetic nephropathy we tried to find a relation between hsCRP as a marker of diabetic nephropathy. In this study, the mean age of patients without nephropathy was 57.14 and mean age of patients with nephropathy was 55.7.In one study by Nikhil Choudhary, Ravinder S Ahlawat the mean age was $55.05 \pm 7$ and $57 \pm 4$ in patients with micro and macro albuminuria respectively ${ }^{10}$.

\section{Hs-CRP and Diabetic Nephropathy}

In our study we found that diabetic patients with nephropathy showed significantly higher levels of HsCRP. This result is in agreement with Picardi et al $14,{ }^{15}$ who reported that patients with recent onset of type 2 DM with nephropathy had higher levels of Hs-CRP as compared to patients without nephropathy ${ }^{15}$. Also, Coulon et $\mathrm{al}^{16}$ proved that diabetic patients have higher levels of cytokines than normal individuals and this elevation might be related to activation of macrophages, increased oxidative stress, or induction of cytokines. So, type $2 \mathrm{DM}$ is now accepted to be a chronic immuno-inflammatory disorder. However, Alexandraki et $\mathrm{al}^{17} \mathrm{did}$ not find any significant difference between 167 type 2 diabetic patients and control group as regards IL-6. In our study we found that low-grade inflammation was already present in the early stage of microalbuminuria, and it was increased with progressive increase of UAE.

In agreement with our results, Picardi et $\mathrm{al}^{15}$ and Piccirillo et $\mathrm{al}^{18}$ who observed that low-grade inflammation was already present in the early stage of micro-albuminuria and low-grade inflammatory markers could serve in predicting initiation, and the progression of diabetic nephropathy. Also Saraheimo et a ${ }^{19}$ reported that low-grade inflammatory markers are associated with diabetic nephropathy in type 2 diabetic patients in which C-reactive protein and interleukin-6 were higher compared to normoalbuminuric patients. On the other hand, contradictory study showed higher CRP concentrations in patients with normoalbuminuria than macroalbuminuria $^{20,21}$. So, the results are conflicting and needs further research to clarify the role of these inflammatory cytokines in diabetic complications. In addition, we found that the level of HbAlc at baseline showed a significant positive correlation with Hs-CRP $(r=0.750, p<0.001)$, in the diabetic group.. Also, we found a significant direct correlation between blood pressure and Hs-CRP and IL-6.. In addition, a study ${ }^{20}$ included 45 consecutive young patients with type 2 diabetes, followed up at a public health assistance centre, and 30 healthy subjects matched by age revealed that inflammatory markers especially CRP are more higher in diabetic hypertensive patients more than normotensive diabetic patients By doing step-wise multiple regression analysis to determine the independent association between potential predictor variables (age, duration of diabetes, waist circumference, CRP level, at baseline), the UAE was the dependent variable, after adjusting for the effect of other variables by partial correlation analysis. Association between UAE and the levels of inflammatory markers of Hs-CRP with $\mathrm{R}^{2}=0.927(\mathrm{p}<0.001)$ and IL-6 with $\mathrm{R}^{2}=0.838(\mathrm{p}<0.001)$ was found.

\section{References}

[1]. Beaglehole R, Yach D: Globalisation and the prevention and control of non- communicable disease: The neglected chronic disease of adults. Lancet 362: 1763-1764, 2003

[2]. Yach D, Hawkes C, Gould C, Hofman K: The global burden of chronic diseases: Overcoming impediments to preventionand control. JAMA 291: 261\&2622, 2004

[3]. Ritz E, Rychlik I, Locatelli F, Halimi S: Endstage renal failure in type 2 diabetes: A medical catastrophe of worldwide mensions. Am J Kidney Dis 34: 795-808, 1999

[4]. Juan F. Navarro-Gonza' lez and Carmen Mora-Fema' ndez: The Role of Inflammatory Cytokines in Diabetic Nephropathy. J Am Soc Nephrol 19: 433442, 2008

[5]. Michael brown lee,Lyoyd P:complications of Diabetes mellitus, Williams textbook of endocrinology, lllh edition, Saunders, 2007: $1443-1450$

[6]. Ritz.E,O1th SR. Nephtopathy in patients with type2diabetes mellitus. N Eng J Med.1999;341:1127-1133.

[7]. Ron Thomas vcrghcsc: Diabetic nephropathy-an Indian perspective, The Lancet student.www.The Lancet studentcom.

[8]. Mohan V, Sandeep S, Deepa R, Shah B, Varghese C. Epidemiology of type 2 diabetes: Indian scenario. Kidney Int. 2006 Dec;70(12):2131-3.

[9]. Hans-Henrik Parving Michael Mauer Eberhard Ritz. Diabetic Nephropathy. The Kidney,Barry M. Brenner and Rector FC. Voll,8`h ed W.B.Saunders,2007;1273-1275

[10]. Nikhil Choudhary, Ravinder S Ahlawat. Interleukin-6 and C-Reactive Proteinin Pathogenesis of Diabetic Nephropathy. IJKD 2008;2:72-9

[11]. Pickup JC, Crook MA. Is type II diabetes mellitus adisease of the innateimmune system? Diabetologia.1998;4111241-8.

[12]. Dalla Vestra M, Mussap M, Gallina P, Doni A, van Hinsbergh VW, Stehouwer CD et al. Acute-phase markers of inflammation and glomemlar structure in patients with type 2 diabetes. J Am Soc Nephrol. 2005;16Suppl 1:S78-82.

[13]. Chow FY, Nikolic-Paterson DJ, Ozols E, Atkins RC,Tesch GH. Intercellularadhesion molecule-1 deficiency is protective against nephropathy in type 2 diabetic db/db mice. J Am Soc Nephrol. 2005;16: 171 1-22. 
[14]. Kelly DJ, Chanty A, Gow RM, Zhang Y, Gilbert RE. Protein kinase Cbeta inhibition attenuates osteopontin expression, macrophage recruitment, and tubulointerstitial injury in advanced experimental diabetic nephropathy. J Am Soc Nephrol. 2005; $16: 165460$

[15]. Hasegawa G, Nakano K, Sawada M. Possible role of tumor necrosis factor and interleukin-1 in the developmentof diabetic nephropathy. Kidney Int. 1991;40I1007-12.

[16]. Navarro JF, Mora C, Rivero A. Urinary protein excretion and serum tumor necrosis factor in diabetic patients with advanced renal failure: effects of pentoxifylline administration. Am J Kidney Dis.1999;33:458-63.

[17]. Myrup B, de Maat M, Rossing P, Gram J, Kluft C, JespersenJ: Elevated fibrinogen and the relation to acute phase response in diabetic nephropathy. Thromb Res 812485 49O,1996

[18]. Schalkwijk CG, Poland DC, van Dijk W, Kok A, Emeis JJ, Drager AM et al:Plasma concentration of C-reactive protein is increased in type I diabetic patients Without clinical macroangiopathy and correlates with markers of endothelial dysfunction Evidence for chronic inflammation. Diabetologia 42: 351-357, 1999

[19]. Jager A, van Hinsbergh VW, Kostense PJ, Emeis JJ, NijpelsG, Dekker JM, Heine RJ, Bouter LM, Stehouwer CD: C-reactive protein and soluble vascular cell adhesion molecule-1 are associated with elevated urinary albumin excretion but do not explain its link with cardiovascular risk. Arterioscler Thromb Vasc Biol 22: 593-598, 2002

[20]. Jager A, van Hinsbergh VW, Kostense PJ, Emeis JJ, Yudkin JS, Nijpels G, Dekker JM, Heine RJ, Bouter LM, Stehouwer CD: von Willebrand factor, C- reactive protein, and 5-year mortality in diabetic and non-diabetic subjects: The Hoorn Study. Arterioscler Thromb Vasc Biol 19: 3071-3078, 1999

[21]. Stehouwer CD, Gall MA, Twisk JW, Knudsen E, Emeis JJ,Parving HH: Increased urinary albumin excretion, endothelial dysfunction, and chronic low-grade inflammation in type 2 diabetes: Progressive, interrelated, and independently associated With risk of death. Diabetes 51: 1 157-1 165,2002

[22]. Saraheimo M, Teppo AM, Forsblom C, Fagerudd J, Groop PH: Diabetic nephropathy is associated with low-grade inflammation in type 1 diabetic patients. Diabetologia 46:1402 - 1407, 2003

[23]. Bruno G, Merletti F, Biggeri A, Bargero G, Ferrero S, PaganoG, Cavallo Perin P: Progression to overt nephropathy in type 2 diabetes: The Casale Monferrato Study. DiabetesCare 26: 2150 —-2155, 2003 